\title{
REVIEW
}

\section{Management of Type 2 Diabetes in Older People}

\author{
Ahmed H. Abdelhafiz $\cdot$ Alan J. Sinclair
}

To view enhanced content go to www.diabetestherapy-open.com

Received: March 11, 2013 / Published online: April 19, 2013

(C) The Author(s) 2013. This article is published with open access at Springerlink.com

\section{ABSTRACT}

The prevalence of diabetes is increasing due to aging of the population and increasing obesity. In the developed world, there is an epidemiologic shift from diabetes being a disease of middle age to being a disease of older people due to increased life expectancy. In old age, diabetes is associated with high comorbidity burden and increased prevalence of geriatric syndromes in addition to the traditional vascular complications. Therefore, comprehensive geriatric assessment should be

A. H. Abdelhafiz ( $₫)$

Department of Elderly Medicine, Rotherham

General Hospital, Moorgate Road,

Rotherham S60 2UD, UK

e-mail: ahmedhafiz@hotmail.com

\section{A. J. Sinclair}

Bedfordshire and Hertfordshire Postgraduate

Medical School, University of Luton, Puteridge Bury

Campus, Hitchin Road, Luton,

Bedfordshire LU2 8LE, UK

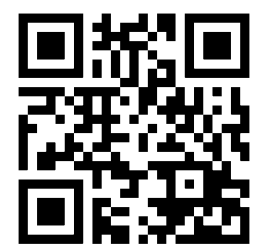

Enhanced content for this article is

available on the journal web site:

www.diabetestherapy-open.com performed on initial diagnosis of diabetes. Due to the heterogeneous nature of older people with diabetes and variations in their functional status, comorbidities, and life expectancy, therapeutic interventions, and glycemic targets should be individualized taking into consideration patients' preferences and putting quality of life at the heart of their care plans.

Keywords: Diabetes mellitus; Geriatric assessment; Glycemic targets; Older people; Management; Type 2 diabetes

\section{INTRODUCTION}

With increasing aging of the population and changes in lifestyle, the prevalence of diabetes is likely to increase, especially among individuals aged $\geq 75$ years. Diabetes is associated with premature morbidity, mortality, and is a substantial health burden on individuals, health systems, and society. Diabetes is the seventh-leading cause of death in the US mainly due to the increased cardiovascular risk [1]. However, in older people diabetes is a disabling disease due to the traditionally associated vascular complications, coexisting multiple 
comorbidities, and the increased prevalence of geriatric syndromes, such as cognitive and physical dysfunction, leading to increased risk of nursing home admission by threefold [2]. Because of the complexity of diabetes in old age and the heterogeneous nature of this age group, comprehensive geriatric assessment is important on the initial examination of older people with diabetes with an individualized goal of therapy aiming to prevent loss of autonomy, and preserve independence and quality of life. This article reviews the management of type 2 diabetes in old age with a focus on various aspects relevant to older people.

\section{METHODS}

The authors performed a search of Medline and Embase from January 1969 to March 2013 using keywords relating to diabetes management in older people. Only English language articles were selected. Articles were reviewed for relevance by abstract. A manual review of citations in retrieved articles was performed in addition to the electronic literature search. The final list of cited references was chosen on the basis of scientific quality and relevance to the topic of review.

\section{EPIDEMIOLOGY}

The increasing prevalence of obesity and global aging of the population implies that the incidence and prevalence of diabetes will continue to rise. The worldwide prevalence of diabetes will double from the year 2000-2030, with the greatest increase in those $>65$ years of age [3]. In France between 2000 and 2009, the prevalence increased with age to $14.2 \%$ in those aged $65-74$ years, peaking at $19.7 \%$ in men and
$14.2 \%$ in women aged $75-79$ years [4]. In the US, total diabetes prevalence is estimated to be $14 \%$ of the population and is highest in those aged $\geq 65$ years, and by the year 2050 diabetes prevalence could be as high as 33\% [5]. However, the prevalence of undiagnosed diabetes remains high. In the National Health and Nutrition Examination Survey (NHANES), the prevalence of diagnosed diabetes in those $\geq 75$ years old was $14.9 \%$, and undiagnosed diabetes based on fasting plasma glucose and 2-h oral glucose tolerance test was $13.4 \%$. This makes a total prevalence of diagnosed and undiagnosed diabetes of $28.3 \%$, and undiagnosed diabetes constitutes a proportion of approximately $47 \%$ [6]. In care homes diabetes affects approximately 20-25\% of residents in the UK [7]. In the US approximately $24.6 \%$ of nursing home residents had diabetes in 2004 [8]. The trend in prevalence increased from 1995 to 2004 $(16.9-26.4 \%$ in males and $16.1-22.2 \%$ in females, $P<0.05$ ) [9]. For the oldest residents (aged $\geq 85$ years), the prevalence increased from $13.1-19.5 \%$ in males $(P=0.02)$ and from $11.3-16.1 \%$ in females $(P=0.04)$ [9]. A more recent survey showed a further increase in the prevalence affecting approximately $32.8 \%$ of residents [10].

\section{ETIOLOGY}

Normal glucose homeostasis requires both normal insulin secretion by beta cells of the pancreas and normal peripheral glucose utilization by peripheral tissues sensitive to insulin. In old age, increased adiposity and decreased physical activity predispose older people to develop insulin resistance [11]. As the muscle tissue is the main site of glucose consumption, the loss of muscle mass or 
sarcopenia associated with aging increases the risk of developing insulin resistance, glucose intolerance, and diabetes [12]. Aging is also associated with impaired insulin secretion [13]. Therefore, in older people with diabetes abnormalities in both insulin sensitivity and insulin secretion underlie the development of type 2 diabetes, which develops gradually, over several years, as a result of progressive deterioration of glucose control from normal glucose tolerance to impaired glucose tolerance, to clinically manifest diabetes. Both insulin resistance and impaired insulin secretion contribute to development of diabetes with a principle defect of insulin secretion in lean individuals and insulin resistance in obese ones. Another factor is the diminished secretion of incretin hormones in patients with type 2 diabetes. The incretin hormones normally reduce blood glucose level by inducing glucose-dependent insulin release and inhibition of glucagon secretion.

\section{CLINICAL PRESENTATION}

Diabetes can be asymptomatic in up to $50 \%$ of older people [14]. However, when symptoms are present they are nonspecific and can be attributed to aging. Nonspecific symptoms, such as being generally unwell, fatigued, or lethargic, are common manifestations of diabetes in old age. Geriatric syndromes may be the first manifestation of diabetes, such as falls and urinary incontinence. Symptoms could also be atypical, such as anorexia, rather than the typical polyphagia. The classic osmotic symptoms of diabetes are usually less prominent due to the increased renal threshold for glucose (reducing the intensity of polyuria) and impairment of thirst sensation (reducing the intensity of polydipsia). Diabetes complications, such as non ketotic hyperosmolar coma, may be the presenting symptom or diabetes may be first diagnosed during an acute illness or a routine blood test.

\section{DIAGNOSIS}

Diabetes is diagnosed if fasting plasma glucose is $\geq 7 \mathrm{mmol} / \mathrm{L}$ or the 2 -h postprandial glucose is $\geq 11.1 \mathrm{mmol} / \mathrm{L}$ regardless of age [15]. However, normal glycemia is defined as fasting plasma glucose $<6.1 \mathrm{mmol} / \mathrm{L}$ or 2 -h postprandial glucose $<7.8 \mathrm{mmol} / \mathrm{L}$. Therefore, the two categories between normal glycemia and diabetes are impaired fasting glycemia (fasting glucose $\geq 6.1$ but $<7 \mathrm{mmol} / \mathrm{L}$ ) and impaired glucose tolerance (2-h post prandial glucose $\geq 7.8$ but $<11.1 \mathrm{mmol} / \mathrm{L}$ ). These two categories are at high risk of developing diabetes and vascular complications [16]. Clinicians should be aware that older people may have normal fasting glucose levels in the early stages of diabetes. Fasting blood glucose is less sensitive in diabetes diagnosis in old age but 2-h glucose tolerance test appears to capture undiagnosed cases [17]. Glycosylated hemoglobin (HbA1c) can be used as a diagnostic test with a cut off level of $\geq 48 \mathrm{mmol} / \mathrm{mol} \mathrm{(} \geq 6.5 \%$ ) for diabetes diagnosis. It has the advantage of convenience to patients, less day-to-day variability, specificity for diabetes, and it is standardized internationally. However, although HbA1c has high specificity $(98.7 \%)$, its low sensitivity (46.8\%) means that it can miss more than half of subjects with diabetes [18].

\section{COMORBIDITY BURDEN}

Chronic conditions are common among older people with diabetes. Patients have at least one comorbid chronic disease in addition to 
diabetes and as many as $40 \%$ of patients have at least three conditions [19]. The comorbidity burden is even higher in care home residents with diabetes. For example, patients have more cardiovascular disease, visual problems, pressure sores, limb amputations, and kidney failure than residents without diabetes [20]. In a retrospective case note review of 75 nursing home residents with diabetes in the UK, very significant levels of disability has been shown in areas of continence, feeding, mobility, and communication. Each individual had a mean of four comorbidities (range 1-8) [21]. The mortality rate reported from this study was high (34\%) after 1-year of follow-up, indicating severe disability and frailty [22]. In another study, residents with diabetes had a greater comorbidity burden (Hierarchical Condition Category 1.90 versus 1.58), more prescribed medications, and experienced more hospitalizations $(37 \%$ versus $18 \%)$ than residents without diabetes [10]. This increased comorbidities in older people with diabetes could be related to the improved survival and decreased cardiovascular mortality [23].

\section{GERIATRIC SYNDROMES}

Geriatric syndromes, such as cognitive and physical dysfunction, depression, and falls and urinary incontinence, are common in older people with diabetes and may have subtle presentations [24]. Due to the effect of diabetes on physical function the risk of disability in performing activities of daily living is increased by twofold compared to those without diabetes [25]. Diabetes is also associated with reduced muscle strength, poor muscle quality, accelerated loss of lower extremity strength, and muscle mass contributing further to physical limitation and frailty [26]. Frailty can be defined as a condition in which an older person is coping just above the threshold of disability; therefore, any physical or psychological stress can lead to loss of independence and overt disability [27]. Diabetes mellitus and insulin resistance increase the likelihood of accelerated aging process and development of frailty [28]. Diabetes complications may contribute to worsening of geriatric syndromes, such as increased risk of falls due to peripheral neuropathy or impaired vision caused by diabetic retinopathy. Unlike other chronic conditions, diabetes care is dependent on the patients' ability to perform self-care tasks, which may be compromised by both cognitive and physical disability. For example, patients with cognitive impairment may not be able to recognize or treat hypoglycemia, or remember and administer their insulin regime correctly. Also, patients with depression may have problems with medication or self-care compliance leading to persistent hyperglycemia and increased risk of diabetic complications [29].

\section{GUIDELINES EVIDENCE}

Guidelines for the management of diabetes in old age do not have the same evidence-base as those for younger diabetic populations due to the exclusion of older people from clinical trials.

\section{Evidence for Glycemic Control}

Tight glycemic control reduces microvascular disease. However, the UK Prospective Diabetes Study (UKPDS) is the only study that showed benefit in reducing macrovascular disease [30]. The more recent randomized controlled trials [31-33] have failed to show a benefit of tight 
glycemic control in reducing macrovascular complications, and mortality rate was significantly higher in the intensive therapy arm of the Action to Control Cardiovascular Risk in Diabetes (ACCORD) trial (5\% versus 4\%) [31]. The lack of benefit on macrovascular risk reduction in these trials could be explained by the relatively older population, longer duration of diabetes, and the high prevalence of already established cardiovascular disease (32-40\%); thus, minimizing the benefit of tight glycemic control. On the other hand, the UKPDS population was relatively younger and the study had included only patients with newly diagnosed diabetes and excluded those with significant cardiovascular disease (Table 1 [30-33]).

\section{Evidence for Older People}

Currently, there is no evidence to suggest that tight glycemic control will have a positive impact on outcomes relevant to older people, such as a delay in cognitive decline or disability $[34,35]$. In fact, low $\mathrm{HbA} 1 \mathrm{c}<53 \mathrm{mmol} / \mathrm{mol}$ $(<7 \%)$ has been shown to increase risk of falls [36]. In frail older patients, the presence of competing comorbidities means that life expectancy and quality of life may be reduced more by other conditions than by diabetes. In a decision analysis to assess the effects of baseline health status on prioritization of intensive control of glucose and blood pressure levels in older patients with type 2 diabetes, intensive blood pressure control conferred a larger benefit than glucose control at advanced ages (75-79 years old), and the expected benefits of both therapies steadily declined as the level of comorbid illness and functional impairment increased [37]. Therefore, guidelines generally recommend strict glucose control in healthier older patients and lax approach in frail patients with multiple comorbidities and high risk of hypoglycemia [38].

\section{MANAGEMENT}

Diabetes management of older people should take into account their heterogonous nature, complex needs, and targets relevant to them should be addressed at the outset considering their goals and wishes, particularly quality of life.

\section{Initial Assessment}

Older people with diabetes should have a comprehensive geriatric assessment on

Table 1 Summary of recently published trials [30-33]

\begin{tabular}{|c|c|c|c|c|}
\hline & $\begin{array}{l}\text { UKPDS } \\
\text { Follow-up [30] }\end{array}$ & ACCORD [31] & ADVANCE [32] & VADT $[33]$ \\
\hline Number of patients & 3,277 & 10,251 & 11,140 & 1,791 \\
\hline Mean (SD) age, years & $62.0(8)$ & $62.2(6.8)$ & $66.0(6)$ & $60.5(9)$ \\
\hline Duration of diabetes on entry, years & Newly diagnosed & 10.0 & 8.0 & 11.5 \\
\hline Cardiovascular outcome & Benefit & Harm & No benefit & No benefit \\
\hline
\end{tabular}

ACCORD Action to Control Cardiovascular Risk in Diabetes, ADVANCE Action in Diabetes and Vascular Disease: Preterax and Diamicron MR Controlled Evaluation, UKPDS UK Prospective Diabetes Study, VADT Veterans Affairs Diabetes Trial 
Table 2 Comprehensive geriatric assessment for older people with diabetes [39]

A. Microvascular complications

Retinopathy Screening for diabetic retinopathy as well as other ocular diseases common in older people, such as cataract, glaucoma, and macular degeneration. Preservation of vision is important to prevent social isolation, reduce incidence of falls, and maintain independence especially for self-medication with insulin

Nephropathy Chronic kidney disease is common in older people. Monitoring of renal function is essential for adjustment of medications. Angiotensin-converting enzyme inhibitors or angiotensin receptor blockers should be used in patients with persistent microalbuminuria

Neuropathy Regular feet inspection and access to diabetic foot care is essential in older people with diabetes as many may not be able to care for their feet due to physical disability

B. Cardiovascular risk factors

Cardiovascular disease is the most common cause of mortality in patients with diabetes regardless of age. Life style modification, such as weight reduction, regular exercise, and smoking cessation, is recommended. Achieving blood pressure and blood glucose control is essential along with dyslipidemia treatment and the use of antiplatelets as a secondary prevention

C. Geriatric syndromes

Screening for the following geriatric syndromes should be addressed on the initial assessment:

Cognition: cognitive impairment should be suspected if difficulties in self-care develop

Physical function: mobility, gait, balance, and ability to perform activities of daily living

Nutrition: oral health, chewing, swallowing, and hydration

Depression: suspected if noncompliance with medication develops

Comorbidity burden

Polypharmacy: medication review to reduce medication burden

Pain: assessment for neuropathic and nonneuropathic pain

Urinary incontinence: could be the first manifestation of diabetes

Social status: the need for help in self-care especially for those on insulin

diagnosis. Geriatric syndromes, such as cognitive and physical dysfunction, are common complications of diabetes in old age in addition to the traditional vascular complications. Therefore, comprehensive geriatric assessment should include screening for microvascular complications, cardiovascular risk factors, and geriatric syndromes (Table 2 [39]).

\section{Life Style Modification and Drug Therapy}

Healthy life style modifications, such as weight reduction in overweight patients, regular exercise, and smoking cessation, are similarly beneficial in older people as they are in younger people. Cardiovascular mortality risk remains high even in older people ( $>75$ years old) with diabetes; therefore, cardiovascular risk 
reduction is recommended in those fit older individuals as in younger people [40]. Special considerations should be undertaken when considering drug therapy in older people with diabetes.

\section{Metformin}

Metformin is a good first-line therapy in older people due to lower risk of hypoglycemia and the potential weight loss in obese patients. However, renal function should be carefully monitored as chronic kidney disease is more common with increasing age. Metformin should be withdrawn if glomerular filtration rate (GFR) drops $\quad<30 \mathrm{~mL} / \mathrm{min} / 1.73 \mathrm{~m}^{2}$. The most common side effects are gastrointestinal, such as nausea, diarrhea, and abdominal pain, which generally occur earlier in treatment; therefore, metformin should be started at a lower dose to test for tolerability. When other conditions common in older people, such as cardiac failure, dehydration, or acute illness, develop, metformin therapy should be reviewed due to increased risk of lactic acidosis.

\section{Sulfonylureas}

Sulfonylureas are reasonable either first-line, if metformin is not tolerated, or add-on therapy. Long-acting sulfonylureas, such as chloropropamide and glibenclamide, should not be used in older people due to risk of hypoglycemia. Shorter-acting agents, such as gliclazide or glipizide, are more suitable. Hypoglycemic episodes should be closely monitored in older people using sulfonylureas. Weight gain is another side effect of sulfonylurea but may be advantageous in frail and underweight patients. Sulfonylureas are metabolized in the liver; therefore, liver function should be monitored regularly.

\section{Pioglitazone}

Pioglitazone is another option as first-line, when metformin and sulfonylureas are not tolerated, or add-on therapy to delay use of insulin. The advantage of pioglitazone in older people is that it can still be used if renal function is impaired and has low risk of hypoglycemia. The main side effects are fluid retention; therefore, it is not suitable for congestive cardiac failure patients with volume overload, and the increased incidence of fractures and possible bladder cancer.

\section{Meglitinides}

Meglitinides are rapid onset and short-acting insulin secretors. They have less hypoglycemic effect but a lesser risk of hypoglycemia than sulfonylureas, and have the advantage of targeting postprandial blood glucose level. They are suitable for older people with high risk of hypoglycemia, especially those with irregular eating patterns. Unlike nateglinide, repaglinide is more effective and can be safely used in patients with renal impairment.

\section{Alpha-Glucosidase Inhibitors}

Alpha-glucosidase inhibitors act by reducing intestinal glucose absorption. They are weak hypoglycemic agents but their low risk of hypoglycemia makes them suitable as add-on therapy for older people. Their common side effects are flatulence and diarrhea, which may limit their use.

\section{Dipeptidyl Peptidase IV Inhibitors}

Dipeptidyl peptidase IV inhibitors are moderately effective as mono- or add-on therapy. They are weight neutral and their major advantage in elderly patients is the absent risk of hypoglycemia; however, their 
doses need to be adjusted according to renal function.

\section{Glucagon-like Peptide-1 Mimetics}

Glucagon-like peptide-1 mimetics are injectable drugs suitable as mono- or add-on therapy. The main advantage in elderly patients is the absent risk of hypoglycemia. They are also associated with weight loss, which may be an advantage in obese individuals. However, gastrointestinal side effects are common and may be associated with the increased incidence of pancreatitis. They are also not suitable for frail patients or those with GFR $<30 \mathrm{~mL} / \mathrm{min} /$ $1.73 \mathrm{~m}^{2}$.

\section{Insulin}

Insulin should be used in elderly patients when drug therapy is not tolerated or insufficient to achieve satisfactory glycemic control. The new long-acting insulin analogs are suitable for older people due to the ease of use and lower risk of hypoglycemia. Older patients and their carers should be adequately educated about symptoms and treatment of hypoglycemia as well as blood glucose monitoring before starting insulin therapy.

\section{Glycemic Targets}

Due to heterogeneity of older people with diabetes, glycemic targets should be individualized taking into consideration the individuals' overall health and life expectancy.

\section{Fit Older People}

For healthier older people with low prevalence of cardiovascular risk factors, especially those with a new diagnosis of diabetes, tight glycemic control with a HbA1c approximately $53 \mathrm{mmol} /$ mol (7\%) is reasonable. The UKPDS follow-up study showed the benefit of improved glycemic control on lowering cardiovascular events in newly diagnosed patients with diabetes and low prevalence of cardiovascular disease [30]. Also, it has been shown that persistent hyperglycemia is associated with the increased risk of mortality [41] and falls [42] regardless of the associated comorbidities.

\section{Frail Older People}

For frail older people or those with established cardiovascular disease, a safer target approximately $58-64 \mathrm{mmol} / \mathrm{mol}(7.5-8.0 \%)$ is appropriate. The presence of multiple comorbidities is a potential competitor for the benefit of tight glycemic control in this population. In a decision analysis to assess the effects of comorbid conditions and functional impairment, the expected benefits of tight glycemic control (HbA1c 53 versus $63 \mathrm{mmol} /$ mol [7.0\% versus $7.9 \%]$ ), declined steadily as the level of comorbidities and functional impairment increased. For example, in patients aged 60-64 years with new onset diabetes, the quality-adjusted days declined from 106 (95\% confidence interval [CI]: 97, 117) days to 44 (range 38-50) days, with 3 additional points in mortality index score and to 8 (range 5-10) days with 7 additional index points [37].

\section{Very Frail Older People}

For very frail older people, and those residents in nursing homes and with a limited life expectancy, a target HbA1c of $64-75 \mathrm{mmol} /$ mol (8-9\%) is appropriate. Tight glycemic control in this population may be harmful by inducing hypoglycemia and reducing quality of life. Also, higher HbA1c $>75 \mathrm{mmol} / \mathrm{mol}$ (>9.0\%) has been shown to be associated with increased mortality [43]. Targets in this population should focus on short-term day-to-day blood glucose levels rather than a long-term HbA1c, due to limited life expectancy, to avoid both 


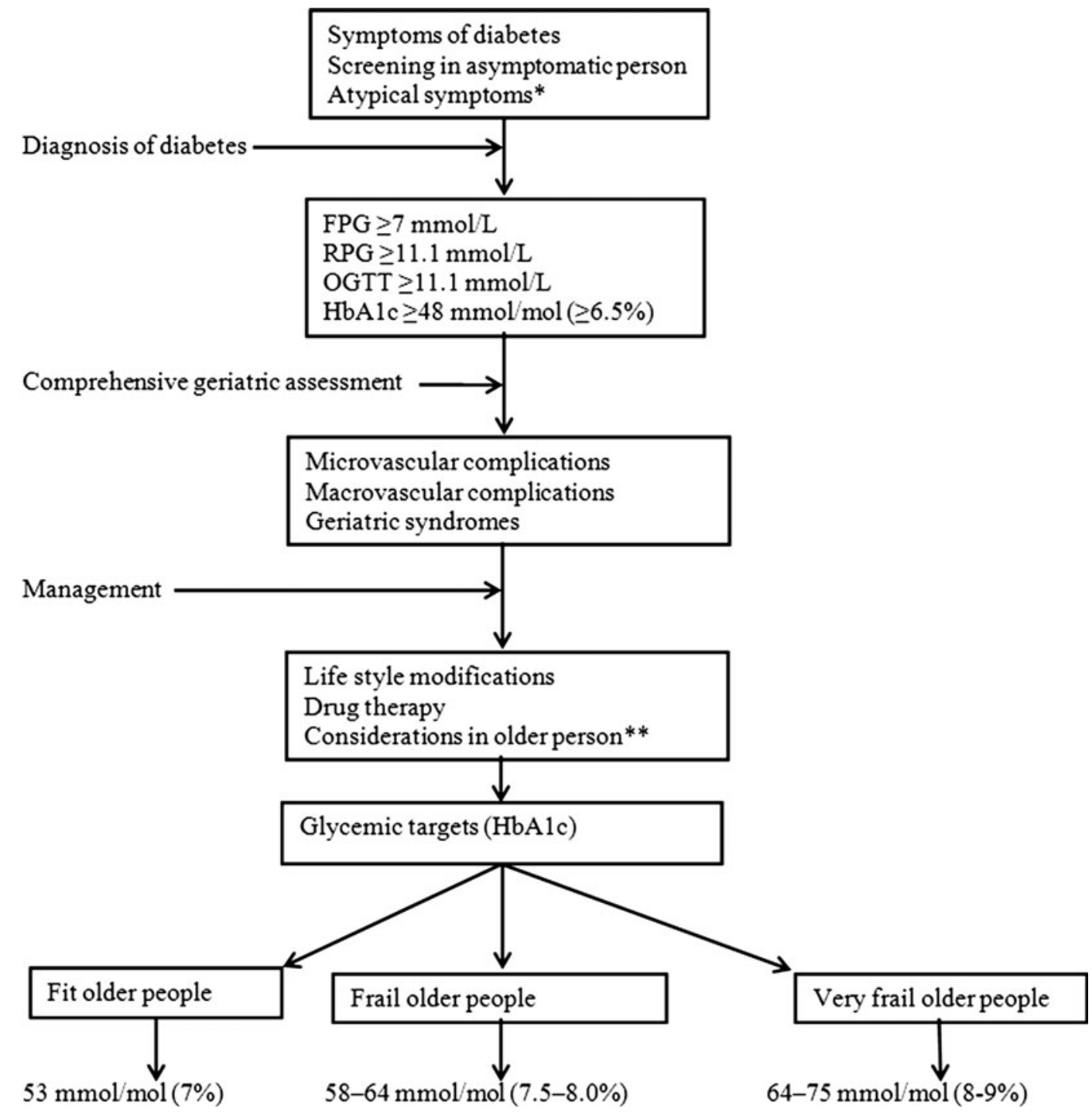

Fig. 1 Diabetes diagnosis and management in older people. *Atypical symptoms may include falls or generally unwell.

${ }^{* *}$ Considerations, such as risk of hypoglycemia and

hyperglycemia, which may lead to lethargy, dehydration, visual impairment, and infections and hypoglycemia, which may lead to falls and confusion (Fig. 1).

\section{Considerations in Older People}

\section{Care Homes}

Care home residents with diabetes are likely to be frail, with multiple comorbidities and impaired cognitive function. $F P G$ fasting plasma glucose, $H b A 1 c$ glycosylated hemoglobin, $R P G$ random plasma glucose, OGTT oral glucose tolerance test.

limited life expectancy. Therefore, short-term glycemic targets with minimal diabetes-related interventions are more important to maintain quality of life. Maintaining a random blood glucose $>4$ but $<15 \mathrm{mmol} / \mathrm{L}$ is a reasonable target as blood glucose outside this range is likely to be symptomatic and results in cognitive changes [44]. Maintaining blood glucose in this "comfort zone" may insure "comfort care" avoiding both hyperglycemia 
and hypoglycemia, which may reduce malaise and improve mental function and general well-being [45]. Care homes should have a policy for diabetes care, including diabetes screening for residents on admission and individualized care plans for residents. Care plans should be tailored to patient needs, which take into consideration patients' values, preferences, their life expectancy, comorbidities, and the impact of diabetes management (polypharmacy, glucose monitoring) on quality of life.

\section{Dementia}

Progressive decline in cognitive function leading to dementia is common in older people with diabetes. The relative risk of Alzheimer's disease is 1.5 (95\% CI: $1.2,1.8)$, and that of vascular dementia is 2.5 (95\% CI: 2.1, 3.0) [46]. The increased prevalence of cardiovascular risk factors, such as hypertension, dyslipidemia, and hyperglycemia, could lead to increased inflammation, oxidative stress and endothelial dysfunction, and increased prevalence of cerebrovascular disease, which may explain the increased risk of vascular dementia with diabetes [47]. On the other hand, insulin dysregulation, protein glycation, amyloid deposition, and direct cerebral glucose toxicity may lead to accelerated brain aging, which may explain the increased risk of Alzheimer's disease in older people with diabetes [48]. Although there is an association between hyperglycemia and cognitive dysfunction, it has been shown that tight glycemic control was not able to prevent a decline in mental function [34]. Older people with diabetes and dementia experience difficulties in performing self-care tasks. It has been shown that once dementia develops diabetes self-care (taking diabetes medication, regular exercise, following a recommended eating plan, blood glucose monitoring, and feet inspection) deteriorates [49]. Patients are also more likely to experience treatment-related complications, such as severe hypoglycemia, requiring assistance [50]. This is important as it may alert the clinicians to screen for cognitive dysfunction if patients' noncompliance with self-care task is observed or recurrent unexplained hypoglycemia occurs. Clinicians should also be aware that dementia may be associated with language impairment, disorientation, and personality changes, which may mimic the symptoms of hypoglycemia [51]. Older people with diabetes and dementia will have complex needs due to increased dependency and unpredictable behavioral changes as the decline in cognitive function continues. For example, hydration should be maintained due to impaired thirst sensation to avoid risk of volume depletion and hyperglycemic crises. In insulin-treated patients, the new class of long-acting insulin analogs may be a good option as they reduce the risk of hypoglycemia and can be conveniently injected once-daily [52]. Patients who have erratic eating patterns and unpredictable caloric intake could be managed with a regime where short-acting insulin analogs are administered only after meal consumption; thus, preventing insulin-induced hypoglycemia if a meal is missed or only partly consumed.

\section{Hypoglycemia}

Older people with diabetes are at increased risk of hypoglycemia even at a comparable glycemic control to younger people due to the associated multiple comorbidities [53, 54]. Older patients may tolerate low blood glucose with no specific symptoms due to diminished autonomic response with old age. Therefore, it is important that patients and carers are educated to recognize the symptoms and to treat hypoglycemia. Educational programs should be 
adapted to patients' and carers' abilities. Medications should be reviewed to switch patients taking longer-acting sulfonylureas into shorter-acting agents and polypharmacy reviewed regularly.

\section{Quality of Life}

Quality of life should be maintained without subjecting frail older people to unnecessary therapeutic interventions. Tight glycemic control, including dietary restriction, frequent blood testing, insulin injections, and polypharmacy, may be a burden leading to additional complications. For example, dietary restriction may cause weight loss, frequent finger sticks and insulin injections may lead to agitation especially in patients with dementia, and polypharmacy increasing risk of falls.

\section{Holistic Approach}

Due to the heterogeneity of older people with diabetes, individualized and a holistic care plan is recommended to address their complex needs, taking into consideration their wishes and preferences, their functional status, and life expectancy with quality of life as the main target.

\section{Nutrition}

Nutritional guidelines should not be too restrictive but tailored to be healthy and to reflect personal preferences. Individuals are free to exercise personal choice with respect to food selection. Diabetes treatment is then adjusted accordingly. The aims of nutritional choices for elderly diabetics include: (1) maintenance of healthy body weight and avoidance of malnutrition; (2) coordinated nutritional needs with glycemic targets and adjustment of diabetes medication, especially if food intake is variable; (3) maintenance of hydration.

\section{CONCLUSION}

Prevalence of diabetes is increasing and aging of population is the main driving factor. Older people with diabetes tend to have multiple comorbidities and develop geriatric syndromes in addition to the traditional cardiovascular complications. Therefore, initial assessment on diagnosis should be comprehensive and include screening for these syndromes, especially cognitive and physical dysfunction. Due to the heterogeneous nature of older people with diabetes, management plans should be individualized with variable glycemic targets from tight control in fit individuals to lax approach in frail ones. Quality of life should be at the center of management plans.

\section{ACKNOWLEDGMENTS}

No funding or sponsorship was received for this study or publication of the article. Dr Abdelhafiz is the guarantor for this article, and takes responsibility for the integrity of the work as a whole.

Conflict of interest. Ahmed H. Abdelhafiz declares no conflict of interest. Alan J. Sinclair declares no conflict of interest.

Open Access. This article is distributed under the terms of the Creative Commons Attribution Noncommercial License which permits any noncommercial use, distribution, and reproduction in any medium, provided the original author(s) and the source are credited.

\section{REFERENCES}

1. Liu L. Changes in cardiovascular hospitalization and comorbidity of Heart failure in the United 
States: findings from the national hospital discharge surveys 1980-2006. Int J Cardiol. 2011;149:39-45.

2. Valiyeva E, Russell LB, Miller JE, Safford MM. Lifestyle-related risk factors and risk of future nursing home admission. Arch Intern Med. 2006;166:985-90.

3. Wild S, Roglic G, Green A, Sicree A, King H. Global prevalence of diabetes: estimates for the year 2000 and projections for 2030. Diabetes Care. 2004;27:1047-53.

4. Ricci $\mathrm{P}$, Blotière $\mathrm{PO}$, Weill $\mathrm{A}$, et al. Diabète traité en France: quelles évolutions entre 2000 et 2009? Bull Epidemiol Hebd. 2010;43:425-31.

5. Boyle JP, Thompson TJ, Gregg EW, Barker LE, Williamson DF. Projection of the year 2050 burden of diabetes in the US adult population: dynamic modeling of incidence, mortality, and prediabetes prevalence. Popul Health Metr. 2010;8:29.

6. Cowie C, Rust KF, Ford ES, et al. Full accounting of diabetes and pre-diabetes in the US population in 1988-1994 and 2005-2006. Diabetes Care. 2009;32:287-94.

7. Aspray TJ, Nesbit K, Cassidy TP, Farrow E, Hawthorne G. Diabetes in British nursing and residential homes: a pragmatic screening study. Diabetes Care. 2006;29:707-8.

8. Resnick HE, Heineman J, Stone R, Shorr RI. Diabetes in US nursing homes, 2004. Diabetes Care. 2008;31:287-8.

9. Zhang X, Decker FH, Luo H, et al. Trends in the prevalence and comorbidities of diabetes mellitus in nursing home residents in the United States: 1995-2004. J Am Geriatr Soc. 2010;58:724-30.

10. Dybicz SB, Thompson S, Molotsky S, Stuart B. Prevalence of diabetes and the burden of comorbid conditions among elderly nursing home residents. Am J Geriatr Pharmacother. 2011;9:212-23.

11. Nieto-Vazquez I, Fernandez-Veledo S, Kramer DK, Vila-Bedmar R, Garcia-Guerra L, Lorenzo M. Insulin resistance associated to obesity: the link TNF-alpha. Arch Physiol Biochem. 2008;114:183-94.

12. Evans WJ. Skeletal muscle loss: cachexia, sarcopenia, and inactivity. Am J Clin Nutr. 2010; 91:1123S-7S.

13. Szoke E, Shrayyef MZ, Messing S, et al. Effect of aging on glucose homeostasis: accelerated deterioration of $\beta$-cell function in individuals with impaired glucose tolerance. Diabetes Care. 2008;31:539-43.
14. Meneilly GS, Tessier D. Diabetes in the elderly. In: Morley JE, van den Berg L, eds. Contemporary endocrinology, endocrinology of aging. Totowa, NJ: Humana Press; 2000. p. 181-203.

15. American Diabetes Association. Report of the expert committee on the diagnosis and classification of diabetes mellitus. Diabetes Care. 2002;25(Suppl 1):S5-20.

16. Barzilay JI, Spiekerman CF, Wahl PW. Cardiovascular disease in older adults with glucose disorders: comparison of American Diabetes Association criteria for diabetes mellitus with WHO criteria. Lancet. 1999;354:622-5.

17. Sinclair AJ, Gadsby R, Penfold S, Croxson SC, Bayer AJ. Prevalence of diabetes in care home residents. Diabetes Care. 2001;24:1066-8.

18. Peter A, Fritsche A, Stefan N, Heni M, Häring HU, Schleicher E. Diagnostic value of hemoglobin A1c for type 2 diabetes mellitus in a population at risk. Exp Clin Endocrinol Diabetes. 2011; 119:234-7.

19. Maddigan SL, Feeny DH, Johnson JA. Healthrelated quality of life deficits associated with diabetes and comorbidities in a Canadian National Population Health Survey. Qual Life Res. 2005;14:1311-20.

20. Duffy RE, Mattson BJ, Zack M. Comorbidities among Ohio's nursing home residents with diabetes. J Am Med Dir Assoc. 2005;6:383-9.

21. Gadsby R, Barker P, Sinclair A. People living with diabetes resident in nursing homes-assessing levels of disability and nursing needs. Diabet Med. 2011;28:778-80.

22. Gadsby R, Barker P, Sinclair A. Death rate of residents with diabetes in nursing homes. Diabet Med. 2011;28:829-30.

23. Tierney EF, Cadwell BL, Engelgau MM, et al. Declining mortality rate among people with diabetes in North Dakota, 1997-2002. Diabetes Care. 2004;27:2723-5.

24. Munshi M, Grande L, Hayes M, et al. Cognitive dysfunction is associated with poor diabetes control in older adults. Diabetes Care. 2006;29:1794-9.

25. Gregg EW, Engelgau MM, Narayan V. Complications of diabetes in elderly people. BMJ. 2002;325:916-7.

26. Volpato S, Bianchi L, Lauretani F, et al. Role of muscle mass and muscle quality in the association between diabetes and gait speed. Diabetes Care. 2012;35:1672-9. 
27. Morley JE, Perry HM, Miller DK. Something about frailty. J Gerontol A Biol Sci Med Sci. 2002;57: M698-704.

28. Kahn AJ. Central and peripheral mechanisms of aging and frailty: a report on the 8th Longevity Consortium Symposium, Santa Fe, New Mexico, May 16-18, 2007. J Gerontol A Biol Sci Med Sci. 2007;62:1357-60.

29. Egede LE. Effect of comorbid chronic diseases on prevalence and odds of depression in adults with diabetes. Psychosom Med. 2005;67:46-51.

30. Holman RR, Paul SK, Bethel MA, Matthews DR, Neil HA. 10-years follow-up of intensive glucose control in Type 2 diabetes. N Engl J Med. 2008;359:1577-89.

31. Action to Control Cardiovascular Risk in Diabetes Study Group; Gerstein HC, Miller ME, Byington $\mathrm{RP}$, et al. Effects of intensive glucose lowering in type 2 diabetes. N Engl J Med. 2008;358:2545-59.

32. ADVANCE Collaborative Group; Patel A, MacMahon $\mathrm{S}$, Chalmers J, et al. Intensive blood glucose control and vascular outcomes in patients with type 2 diabetes. N Engl J Med. 2008;358:2560-72.

33. Duckworth W, Abraira C, Mortiz T, et al. VADT Investigators. Glucose control and vascular complications in veterans with type 2 diabetes. N Engl J Med. 2009;360:129-39.

34. Launer LJ, Miller ME, Williamson JD, et al. ACCORD MIND investigators. Effects of intensive glucose lowering on brain structure and function in people with type 2 diabetes (ACCORD MIND): a randomised open-label substudy. Lancet Neurol. 2011;10:969-77.

35. Pham M, Pinganaud G, Richard-Harston S, Decamps A, Bourdel-Marchasson I. Prospective audit of diabetes care and outcomes in a group of geriatric French care homes. Diabetes Metab. 2003;29:251-8.

36. Nelson JM, Dufraux K, Cook PF. The relationship between glycaemic control and falls in older adults. J Am Geriatr Soc. 2007;55:2041-4.

37. Huang ES, Zhang Q, Gandra N, Chin MH, Meltzer DO. The effect of comorbid illness and functional status on the expected benefits of intensive glucose control in older patients with type 2 diabetes: A decision analysis. Ann Intern Med. 2008;149:11-9.

38. American Diabetes Association. Executive summary: standards of medical care in diabetes2010. Diabetes Care. 2010;33:S4-10.

39. Abdelhafiz AH, Sinclair AJ. Tailor treatment in the older patient with type 2 diabetes. Practitioner. 2013;257:21-5.
40. Kronmal RA, Barzilay JI, Smith NL, et al. Mortality in pharmacologically treated older adults with diabetes: the Cardiovascular Health Study, 1989-2001. PLoS Med. 2006;3:e400.

41. Blaum CS, Volpato S, Cappola AR, et al. Diabetes, hyperglycaemia and mortality in disabled older women: the Women's Health and Ageing Study I. Diabet Med. 2005;22:543-50.

42. Schwartz AV, Vittinghoff E, Sellmeyer DE, et al; Health, Aging, and Body Composition Study. Diabetes-related complications, glycaemic control, and falls in older adults. Diabetes Care. 2008;31:391-6.

43. Huang ES, Liu JY, Moffet HH, John PM, Karter AJ. Glycemic control, complications, and death in older diabetic patients: the diabetes and aging study. Diabetes Care. 2011;34:1329-36.

44. Cox DJ, Kovatchev BP, Gonder-Frederick LA, et al. Relationships between hyperglycemia and cognitive performance among adults with type 1 and type 2 diabetes. Diabetes Care. 2005;28:71-7.

45. Lee SJ, Eng C. Goals of glycemic control in frail older patients with diabetes. JAMA. 2011;305:1350-1.

46. Cheng G, Huang C, Deng H, Wang H. Diabetes as a risk factor for dementia and mild cognitive impairment: a meta-analysis of longitudinal studies. Intern Med J. 2012;42:484-91.

47. Middleton LE, Yaffe K. Promising strategies for the prevention of dementia. Arch Neurol. 2009;66: $1210-5$.

48. Biessels GJ, Staekenborg S, Brunner E, Brayne C, Scheltens P. Risk of dementia in diabetes mellitus: a systematic review. Lancet Neurol. 2006;5:64-74.

49. Feil DG, Zhu CW, Sultzer DL. The relationship between cognitive impairment and diabetes selfmanagement in a population-based community sample of older adults with Type 2 diabetes. J Behav Med. 2012;35:190-9.

50. Bruce DG, Davis WA, Casey GP, et al. Severe hypoglycaemia and cognitive impairment in older patients with diabetes: the Fremantle Diabetes Study. Diabetologia. 2009;52:1808-15.

51. Sinclair A, Armes DG, Randhawa G, Bayer AJ. Caring for older adults with diabetes mellitus: characteristics of carers and their prime roles and responsibilities. Diabet Med. 2010;27:1055-9.

52. Rosentock J, Daily G, Massi-Benedetti M, Fritsche A, Lin Z, Salzman A. Reduced hypoglycaemia risk with insulin glargine: a meta-analysis comparing insulin glargine with human NPH insulin in type 2 diabetes. Diabetes Care. 2005;28:950-6. 
53. Abdelhafiz AH, Sinclair AJ. Hypoglycemia in residential care homes. Br J Gen Pract. 2009;59: 49-50.

54. Bramlage P, Gitt AK, Binz C, Krekler M, Deeg E, Tschöpe D. Oral antidiabetic treatment in type-2 diabetes in the elderly: balancing the need for glucose control and the risk of hypoglycaemia. Cardiovasc Diabetol. 2012;11:122. 